\title{
Prediction of new Hsp90 inhibitors based on 3,4-isoxazolediamide scaffold using QSAR study, molecular docking and molecular dynamic simulation
}

\author{
Maryam Abbasi ${ }^{1}$, Hojjat Sadeghi-Aliabadi ${ }^{1 *}$ and Massoud Amanlou ${ }^{2 *}$
}

\begin{abstract}
Background: Heat shock protein90 (Hsp90) are overexpressed in tumor cells, so the inhibition of the Hsp90 ATPase activity would be a significantly effective strategy in cancer therapy.

Methods: In the current study, 3,4-isoxazolediamide derivatives were suggested as an Hsp90 inhibitor for anti-cancer therapy. Multiple linear regression (MLR) and genetic algorithm of partial least square (GA-PLS) methods were performed to build models to predict the inhibitory activity of Hsp90. The leave-one out (LOO) cross-validation and Y-randomization tests were performed to models' validation. The new ligands were monitored by applicability domain. Molecular docking studies were also conducted to evaluate the mode of interaction of these compounds with Hsp90. Identification of the likely pathways into the active site pocket and the involved residues were performed by CAVAER 3.0.1 software. According to QSAR models and docking analysis, three new compounds were predicted. 50 ns molecular dynamic simulation was performed for the strongest synthesized compound and the best predicted compound in terms of binding energy and interactions between ligand and protein.
\end{abstract}

Results: The made models showed the significance of size, shape, symmetry, and branching of molecules in inhibitory activities of Hsp90. Docking studies indicated that two hydroxyl groups in the resorcinol ring were important in interacting with Asp93 and the orientation of these groups was related to substitution of different $R_{1}$ groups. Comparing of molecular dynamic simulation (MDs) results shows that new compound perched in active site with lower binding energy than the best synthesized compound.

Conclusion: The QSAR and docking analyses shown to be beneficial tools in the proposal of anti-cancer activities and a leader to the synthesis of new Hsp90 inhibitors based 3,4-isoxazolediamide. The MDs confirmed that predicted ligand is steady in the Hsp90 active sites.

Keywords: Hsp90, Inhibitor, 3,4-Isoxazolediamide, QSAR, Molecular docking, Molecular dynamic simulation

\footnotetext{
* Correspondence: sadeghi@pharm.mui.ac.ir; amanlou@tums.ac.ir

'Department of Medicinal Chemistry, Faculty of Pharmacy, Isfahan University

of Medical Sciences, Isfahan 81746-73461, Iran

${ }^{2}$ Computational Chemistry Group, Pharmaceutical Sciences Research Center

and Department of Medicinal Chemistry, Faculty of Pharmacy, Tehran

University of Medical Sciences, Tehran, Iran
}

(c) The Author(s). 2017 Open Access This article is distributed under the terms of the Creative Commons Attribution 4.0 International License (http://creativecommons.org/licenses/by/4.0/), which permits unrestricted use, distribution, and reproduction in any medium, provided you give appropriate credit to the original author(s) and the source, provide a link to the Creative Commons license, and indicate if changes were made. The Creative Commons Public Domain Dedication waiver (http://creativecommons.org/publicdomain/zero/1.0/) applies to the data made available in this article, unless otherwise stated. 


\section{Background}

Heat shock proteins (Hsps) play a critical role in maturation and stabilization of proteins in the cell [1]. One of the important Heat shock proteins in cell is Hsp90. The Hsp90 molecular chaperone contributes to folding of more than 200 proteins (client proteins) and it is necessary for adjusting the balance between the synthesis and degradation of many proteins in the cell [2, 3]. The homo dimer of Hsp90 possess three main domains: the $\mathrm{N}$-terminal domain that contains the nucleotide-binding pocket, the middle region that is involved in binding of client proteins and the C-terminal domain that is the dimerization site [4]. The Hsp90 function is reliant on its ability to bind and hydrolyze ATP at the N-terminal domain. First, client protein and co-chaperones bind to Hsp90 in the open condition of protein and then ATP binds to N-terminal and Hsp90 will be closed. Finally, ATP is hydrolyzed, the complex is changed and client protein is folded (Fig. 1) [5].

In tumor cells, Hsp90 is overexpressed and causes the uncontrolled proliferation of transformed cells [6], so inhibition of the Hsp90 ATPase activity can be a significantly effective strategy in cancer therapy [7]. Hsp90 inhibitors are classified into several categories containing natural inhibitors (geldanamycin, GM (1), and radicicol (2)), reclaimed analogues of GM (17-AAG (3) and 17DMAG (4), synthetic inhibitors (purine (PU3 (5)), pyrazole (6), indazole (7), aminoquinolines (SID: 24724290

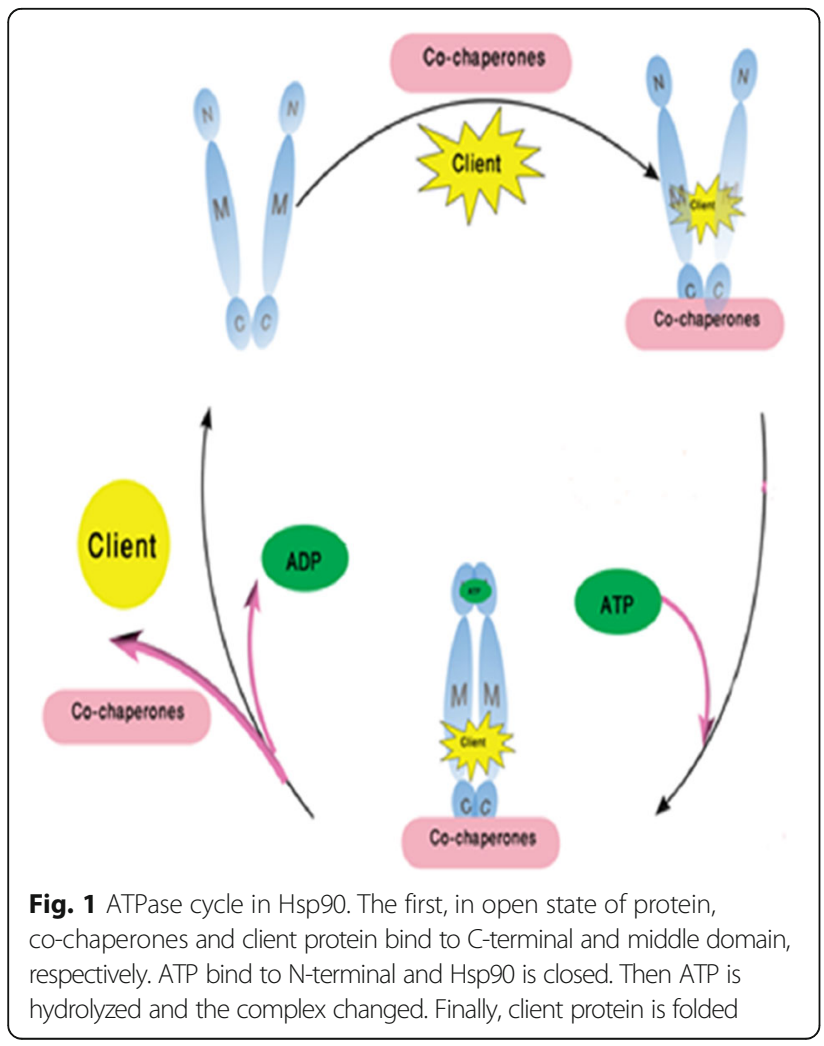

(8)) and isoxazole (9) that are shown in Fig. 2 [8-11]. Some of these inhibitors, such as the reclaimed analogue of geldanamycin (17-AAG), carbazol-4-one benzamide derivative (SNX-5422) and isoxazole derivative (NVP-AUY922, currently known as Luminespib), have been assessed in humans (Fig. 3) [1]. Among the different azaheterocyclic ring systems, the isoxazole scaffold is one of the most promising heterocyclic systems [12]. Baruchello and coworkers in 2011 synthesized novel 3, 4-isoxazolediamides as potent inhibitors of Hsp90 [8].

Forasmuch as obtaining a new inhibitor requires much time and capital, any tool that can help to precipitate the drug development processes would be very noteworthy [13]. The advanced computational techniques are highly useful strategies to conduct rapid and inexpensive investigations on large databases and obtaining new inhibitors [14].

Molecular docking, molecular dynamic simulation and quantitative structure activity relationships (QSARs) are helpful computational methods for drug design and activity prediction $[15,16]$. In molecular docking and molecular dynamic simulation, the 3D structure of the receptor will be available and receptor-ligand interactions play an important role, so this drug design is called structurebased drug design [17]. Docking is a method which proposes the favored orientation and energy of one ligand when bound in the active site to build a stable complex. To investigate interactions between ligand and protein, molecular dynamic simulation will be performed.

QSAR is referred to as ligand-based drug design because it is performed based on the knowledge about ligands [18]. QSAR models are mathematical equations that create relationships between chemical structures and their biological activities without considering a receptor.

In the present study, we performed a QSAR study for modeling the inhibitory effects of 50 synthesized 3,4-isoxazolediamides [8]. Multiple linear regression (MLR) and genetic algorithm of partial least square (GA-PLS) methods were used for modeling the relationship between $\mathrm{pIC}_{50}$ and their structural descriptors. Molecular docking was performed for 25 compounds and the results were compared with experimental data. According to QSAR models and molecular docking analysis three compounds were predicted. Molecular dynamic simulation method was chosen to compare the best synthesized and the best predicted compound in terms of binding energy and interactions between protein and ligand.

\section{Methods}

Activity data and generation of descriptors

In the current study, the Hsp90 inhibitory activity of 50 compounds that were synthesized and evaluated by Baruchello and coworkers, were used as the biological 


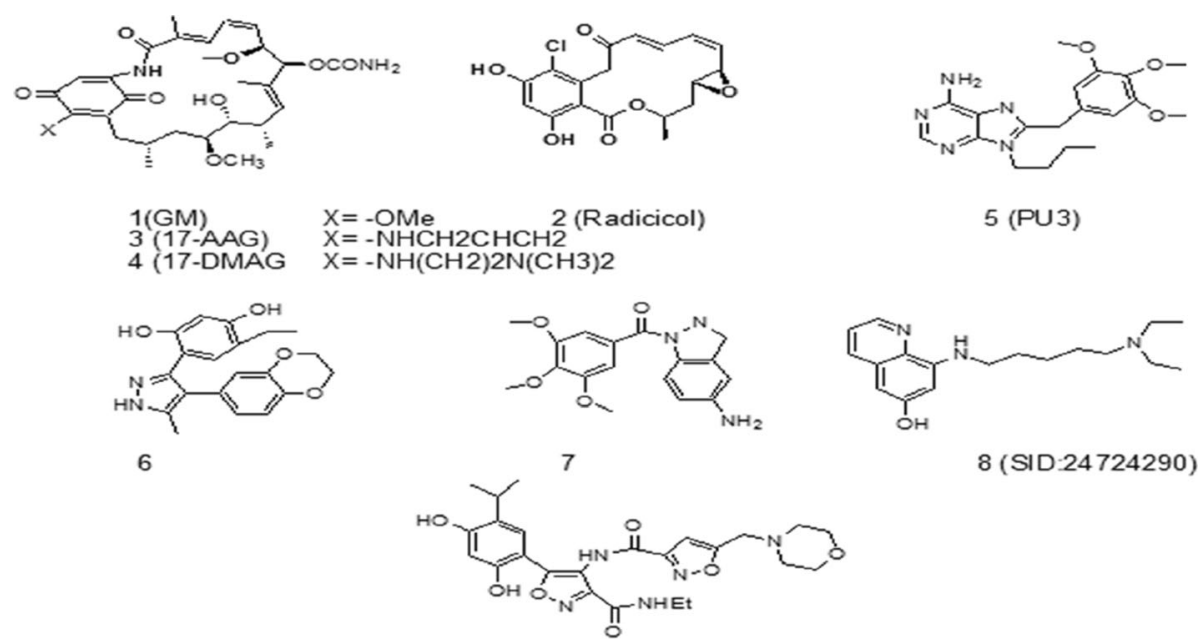

Fig. 2 Several categories of Hsp90 inhibitors. Natural inhibitors (geldanamycin, GM, (1), radicicol (2)), reclaimed analogues of GM (17-AAG (3) and 17-DMAG (4)), synthetic inhibitors (purine (5, PU3), pyrazole (6), indazole (7), aminoquinolines (8, SID: 24724290) and isoxazole (9))

data [8]. To make the mistake less, the compounds were chosen from an article with the same assay. Reported compounds were chosen from isoxazole derivatives. The lead of these compounds was NVP-AUY922 (currently known as Luminespib) that was entered into clinical trials and many of its derivatives were synthesized up to now. These compounds are shown in Table 1.

Geometry optimization was performed by two methods: $\mathrm{MM}^{+}$molecular mechanic force field and the semi-empirical PM3 by HyperChem 8.0 software. Both optimizations were carried out by the Polak-Ribiere algorithm until the root mean square gradient reached $0.01 \mathrm{kcal} / \AA$ mol. Chemical descriptors were also generated by HyperChem software.

HyperChem outputs were conveyed to DRAGON package to compute four classes of descriptors: 0D, 1D, 2D and 3D. Different quantum chemical descriptors were obtained by Gaussian98 program [19]. All of the calculated descriptors are shown in Table 2.

\section{Data processing and model building}

All of the calculated descriptors were used to generate a $50 \times 1126$ data matrix; the number on its rows is illustrative of molecule numbers and the numbers on columns accounts for descriptors. The columns which had constant and near constant amounts were deleted from this data matrix. Since as the models were disrupted by collinear variables, collinear descriptors had to be found and eliminated and then descriptors' correlations with one another and with activity data were checked. In couples with collinearities higher than 0.9 , the highest correlation with the activity was kept and the rest were eliminated. The number of total descriptors for each molecule attained 352 .

The data set (50 compounds) was divaricated into the calibration set and validation set. Validation subset was prepared from $20 \%$ of the total data (here, 9 biological activity data). The model was made by MLR analysis, with the stepwise regression SPSS (Version 12.0) software.

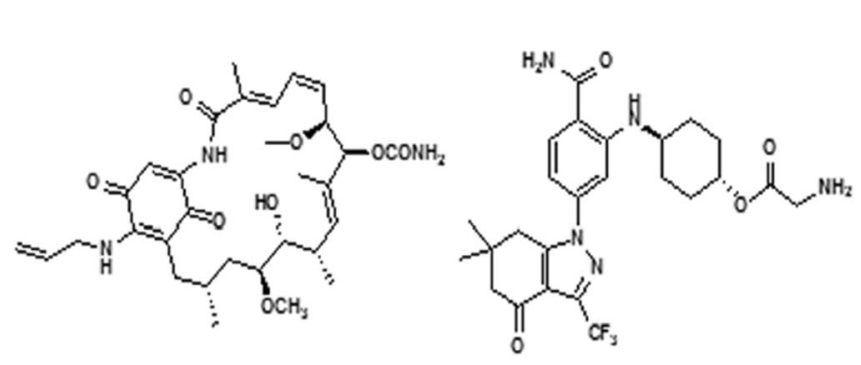

17-AAG
SNX-5422<smiles>CCNC(=O)c1noc(-c2cc(C(C)C)c(O)cc2O)c1-c1ccc(CN2CCOCC2)cc1</smiles>

NVP-AUY922

Fig. 3 The structure of three clinically Hsp90 inhibitors evaluated in human. Derivative of geldanamycin (17-AAG), carbazol-4-one benzamide (SNX-5422) and isoxazole (NVP-AUY922) 
Table 1 Chemical structures of 3, 4-isoxazolediamides derivatives as Hsp90 inhibitors

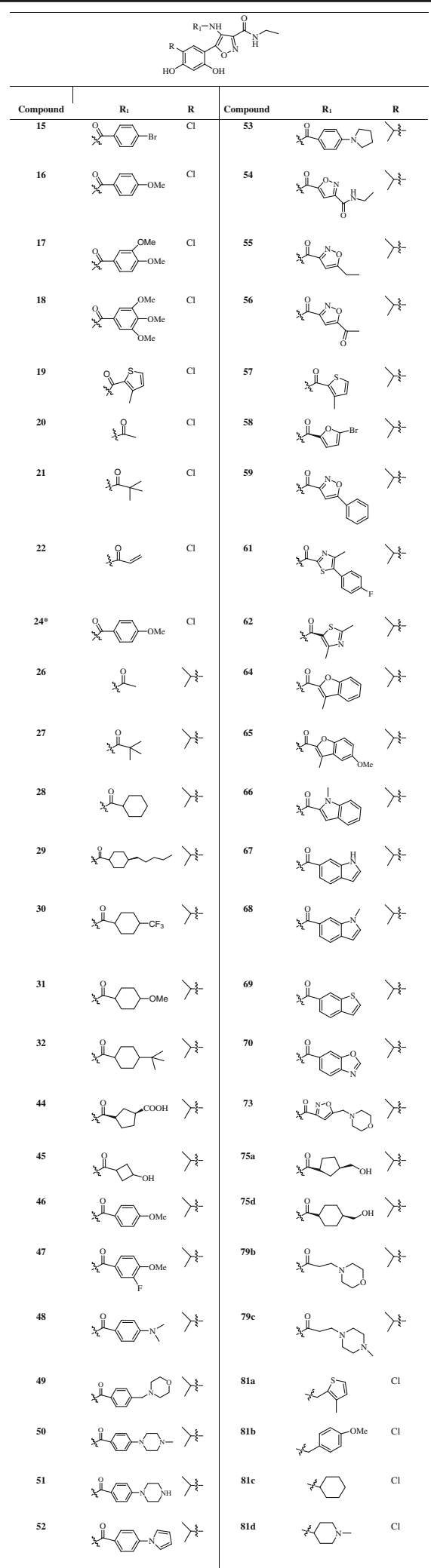

* $\mathrm{NHCH}_{2} \mathrm{CH}_{2}$ converted to $\mathrm{NHCH}_{2} \mathrm{CF}_{3}$
Table 2 Brief of used descriptors in this study

\begin{tabular}{|c|c|}
\hline Descriptor type & Molecular description \\
\hline Chemical & $\begin{array}{l}\text { Surface area, molecular volume, } \\
\text { hydration energy, octanol/water } \\
\text { partition coefficient (logP), } \\
\text { molar refractivity, molar } \\
\text { polarisability and molar mass. }\end{array}$ \\
\hline $0 \mathrm{D}, 1 \mathrm{D}, 2 \mathrm{D}$ and $3 \mathrm{D}$ & $\begin{array}{l}28 \text { constitutional descriptors, } \\
10 \text { functional groups, } \\
18 \text { atom-centered fragments, } \\
216 \text { topological descriptors, } \\
15 \text { molecular walk counts, } \\
64 \text { BCUT descriptors, } \\
24 \text { Galvestopol. charge indices, } \\
96 \text { 2D autocorrelations, } \\
14 \text { charge descriptors, } \\
41 \text { Randic molecular profiles, } \\
27 \text { geometrical descriptors, } \\
150 \text { radial distribution function } \\
\text { descriptors (RDF), } 160 \text { 3D-MoRSE } \\
\text { descriptors, } 99 \text { WHIM descriptors } \\
\text { and } 196 \text { GETAWAY descriptors }\end{array}$ \\
\hline Quantum chemical & $\begin{array}{l}\text { Highest occupied molecular orbital } \\
\text { energy (EHOMO), lowest unoccupied } \\
\text { molecular orbital energy (ELUMO), } \\
\text { molecular dipole moment and local } \\
\text { charge were obtained with PM3 } \\
\text { method in Gaussian } 98 \text {. Hardness } \\
(\eta=0.5(E H O M O+\text { ELUMO)), } \\
\text { softness }(S=1 / \eta) \text {, electronegativity } \\
(x=0.5(E H O M O-E L U M O)) \text { and } \\
\text { electrophilicity }(\omega=x 2 / 2 \eta)\end{array}$ \\
\hline
\end{tabular}

The combined data splitting feature selection (CDFS) approach was utilized because the data splitting has a significant effect on the terminal selected model [15]. In the CDFS approach, numerous subdivisions of the calibration and validation set were created (5 times). In each case, the best model was elected. The chosen models were validated by leave-one out (LOO) cross-validation method. According to 5 models descriptors, general model was created and Y-randomization test was performed to check their predictability.

\section{Molecular docking}

Molecular docking of 3,4-isoxazolediamide derivatives (25 compounds) as Hsp90 inhibitors was perused by AutoDock 4.2 program to detect their binding site, the best direction and the binding energy [20]. Between the experimental Xray structures of Hsp90, the crystallography structure with a PDB entry code of 3OWD was chosen [21].

For protein preparation, the co-crystallized ligand and water molecules, except the water molecules that were significant in interaction between the ligand and protein, were deleted. By AutoDockTools, all missing hydrogens were added. The Kollman atom charges were calculated, non-polar hydrogens merged and the file saved as pdbqt. A grid box was created with a grid point spacing of $0.375 \AA$ and $90 \times 90 \times 90$ points, which included not 
only the active site of the protein but also significant regions of the surrounding surface. Before calculating the grid maps by AutoGrid 4.2 [22], the parameters of the water molecules were added to AD4-bound and AD4parameter files.

After the ligands were prepared, the 3D structures of all compounds were dragged in Marvin Sketch Ver. 5.7, ChemAxon [23]. The partial charges of atoms were computed by the Gasteiger-Marsili procedure and nonpolar hydrogens of the compounds were merged [24].

The Lamarckian genetic algorithm approach was elected for the global optimum binding position. Docking computing parameters were determined as the following: number of Lamarckian job $=50$, initial population $=150$, maximum number of energy evaluation $=25 \times 10^{5}$, and the default values of other parameters were kept unchanged. The docking parameter file (.dpf) was created. The docking procedure was done by AutoDock 4.2 and the .dlg file was generated. All of the runs were ranked by the maximum number of clusters and the lowest binding energy and were analyzed to find the best conformation of the ligand with key residues in the active site of the protein by Accelrys Discovery Studio 2.5 [25] and PyMOL software [26].

\section{Caving active site tunnels}

To monitor likely pathways into the active site pocket of the protein and also recognize the involved residues, CAVAER 3.0.1 software was employed [27]. Likely entrances were searched by assigning maximum probe radius to $0.9 \AA \hat{A}$, shell depth to 4 , and clustering threshold to $3.5 \hat{A}$.

\section{Molecular dynamic simulation}

Molecular dynamic simulation was carried out with the GROMACS 5.0.5 package [28]. The topology parameters of the best predicted ligand in terms of the energy and interaction between ligand and protein were created by the PRODRG web server [29]. The generated charges by this server were corrected by Gaussian 98 program. The pKa for residues of protein were obtained by the PROPKA 3.1 web server to determined which residue was more possible to embrace nonstandard ionization states [28]. The key crystallographic water molecules in the active site were kept [25]. The GROMOS96 54a7 force field and the simple point charges (SPC) water model were used to create protein topology parameters. The complex of ligand and protein was dunked in dodecahedron box with a minimum distance of $1 \mathrm{~nm}$ between the protein surface and box border, containing of about 8250 solvent molecules. By displacing solvent water molecules with $4 \mathrm{Na}+$ was neutralized the system net charge. The energy minimization was done to release spatial clashes of the complex in two steps. First, only water molecules were minimized by using 10,000 steepest descents steps while the other atoms were hold fixed at their initial configuration. After that, the entire system was minimized. To equilibrate the system at a constant temperature of $300 \mathrm{~K}$ was performed NVT step by a 500 ps MD run. After the stabilization of temperature by the V-Rescale algorithm, an NPT ensemble was done with time duration of $1 \mathrm{~ns}$. This was followed by MD production run at 1 bar pressure and 100, 200 and $300 \mathrm{~K}$ temperatures for 1, 2 and $50 \mathrm{~ns}$, respectively. Long-range electrostatic interactions were computed with the Particle Mesh Ewald (PME) method. The linear constraint (LINCS) algorithm was used for covalent bond constraints. Structure visualization was carried out by VMD 1.8.6 and PyMOL.

\section{Result and discussion}

\section{Multiple linear regression analysis (MLR)}

Stepwise regression method was used to select the most appropriate set of descriptors for each type of the split data. Models were selected; of course, some of them could be over-fitted. Another method which could be utilized to select the model or the most suitable correlation equation was the cross-validation method. In this case, the obtained models were evaluated for over-fitting by leave-one-out cross-validation (LOO) method and then were consistently graded for cross-validation $\left(\mathrm{Q}_{\mathrm{LOO}}^{2}\right)$ by the square correlation coefficient. Eventually, one model with equilibrium between the highest $R_{c}^{2}$ and $\mathrm{Q}_{\mathrm{LOO}}^{2}$ was chosen for future analysis.

MLR method was performed five times by distinct split data. In each case, one model was offered. The best five models are reported in Table 3. The models demonstrate high statistical qualities. All of the models have $\mathrm{Q}_{\mathrm{LOO}}^{2}$ greater than 0.5; hence, the expected models indicated suitable results for the prediction set. The values of prediction correlation coefficient $\left(R_{p}^{2}\right)$ for the five final models are documented in Table 3.

The total number of descriptors that existed in all five models was 25 . These descriptors are briefly defined in Table 4. Among these, X5A and 3D-MoRSE descriptors have been repeated in four models. This means that connectivity indices (X5A) and 3D-MoRSE descriptors have main effect on Hsp90 inhibitors which are based on 3, 4-isoxazolediamide scaffold. Some of the descriptors such as Du, BELe1, RDF140m, Gu, ISH, Ku, P2m, and TIE were observed only in one model, and have a lower effect on Hsp90 inhibitors.

To generate a general model for split data, all of the 25 descriptors were applied and MLR analysis was conducted with the stepwise variable selections. The resulted model is reported in MLR equation: 
Table 3 The best five models were selected for future analysis

\begin{tabular}{|c|c|c|c|c|c|c|}
\hline NO. & Descriptors used & $R_{c}^{2}{ }^{a}$ & S.E ${ }^{b}$ & $R_{p}^{2}{ }_{p}$ & $Q^{2 d}$ & $\mathrm{RMS}_{\mathrm{CV}}^{\mathrm{e}}$ \\
\hline 1 & X5A, HATS4u, Mor10m, Mor26p, Mor09u, Du & 0.806 & 0.249 & 0.958 & 0.723 & 0.276 \\
\hline 2 & BELe1, MATS6e, Gu, Mor27p, Mor12m, RDF140m & 0.760 & 0.266 & 0.817 & 0.586 & 0.329 \\
\hline 3 & X5A, T (N..O), dipole y, R3e+, R1e, Mor09m & 0.768 & 0.214 & 0.911 & 0.683 & 0.254 \\
\hline 4 & X5A, HATS4u, Mor26p, TIE, dipole z, Mor26e, ISH & 0.814 & 0.245 & 0.883 & 0.723 & 0.274 \\
\hline 5 & X5A, T (N..O), MATS1p, dipole z, MATS8e, Ku, P2m & 0.790 & 0.252 & 0.944 & 0.696 & 0.278 \\
\hline
\end{tabular}

${ }^{a} R^{2}{ }_{c}=$ Correlation Coefficient of calibration set. ${ }^{b} \mathrm{~S} . \mathrm{E}=$ Standard error of regression. ${ }^{C} \mathrm{R}_{\mathrm{p}}=$ Correlation Coefficient of prediction set. ${ }^{\mathrm{d}} \mathrm{Q}^{2}=$ Leave-one-out cross-validation correlation coefficient. ${ }^{\mathrm{R} M S E_{\mathrm{CV}}}=$ Root mean square error of cross validation

$$
\begin{aligned}
\mathrm{pIC}_{50}= & 16.977( \pm 1.966)-176.806( \pm 28.236) \mathrm{X} 5 \mathrm{~A} \\
& -4.366( \pm 1.046) \text { HATS4u-1.951 }( \pm 0.549) \text { Mor26p } \\
& +0.001( \pm 0.00) \text { TIE }+0.227( \pm 0.069) \text { dipole } \mathrm{z} \\
& +0.863( \pm 0.368) \text { Mor26e }
\end{aligned}
$$

$\left(\mathrm{N}=41, \mathrm{R}^{2}{ }_{\mathrm{c}}=0.771, \mathrm{~S} . \mathrm{E}=0.267, \mathrm{Q}^{2}{ }_{\mathrm{LOO}}=0.637, \mathrm{RMS}_{\mathrm{CV}}=0.297\right)$

Where $\mathrm{N}$ demonstrates the number of molecules used in the calibration set. $\mathrm{R}_{\mathrm{c}}^{2}$ and $\mathrm{Q}_{\mathrm{LOO}}^{2}$ are respectively the squared correlation coefficient for calibration and cross- validation. In addition, S.E is standard error of calibration and $\mathrm{RMS}_{\mathrm{CV}}$ is root mean square error of cross-validation.

In this equation, X5A, HATS4u and Mor26p have a minus, which indicates that the $\mathrm{pIC}_{50}$ is inversely related to these descriptors. Among these, X5A has a main effect on 3, 4-isoxazolediamide Hsp90 inhibitors. Connectivity indices, such as X5A, are among topological indices that are numerical quantifiers of molecular topology and

\begin{tabular}{|c|c|c|}
\hline NO. & Name & Description \\
\hline 1 & $\times 5 \mathrm{~A}$ & Connectivity indices-average connectivity index of order 5. \\
\hline 2 & HATS4u & GETAWAY descriptors-leverage-weighted autocorrelation of lag 4 / unweighted. \\
\hline 3 & Mor10m & 3D-MoRSE descriptors-signal 10 / weighted by mass. \\
\hline 4 & Mor26p & 3D-MoRSE descriptors-signal 26 / weighted by polarizability. \\
\hline 5 & Mor09u & 3D-MoRSE descriptors-signal 09 / unweighted. \\
\hline 6 & Du & WHIM descriptors-D total accessibility index / unweighted. \\
\hline 7 & BELe1 & Lowest eigenvalue n. 1 of Burden matrix / weighted by atomic Sanderson electronegativities. \\
\hline 8 & MATS6e & Moran Autocorrelation-lag 6/weighted by atomic Sanderson electronegativities. \\
\hline 9 & $\mathrm{Gu}$ & WHIM descriptors-total symmetry index / unweighted. \\
\hline 10 & Mor27p & 3D-MoRSE descriptors-signal 27 / weighted by polarizability. \\
\hline 11 & Mor12m & 3D-MoRSE descriptors-signal 12 / weighted by mass. \\
\hline 12 & RDF140m & Radial Distribution Function-140 / weighted by mass. \\
\hline 13 & $\mathrm{~T}(\mathrm{~N} . . \mathrm{O})$ & 2D Atom Pairs-sum of topological distances between N..O. \\
\hline 14 & Dipole y & An electric dipole is located along the y axis. \\
\hline 15 & $\mathrm{R} 3 \mathrm{e}+$ & GETAWAY descriptors-R maximal autocorrelation of lag 3 / weighted by Sanderson electronegativity. \\
\hline 16 & R1e & GETAWAY descriptors-R autocorrelation of lag 1 / weighted by atomic Sanderson electronegativities \\
\hline 17 & Mor09m & 3D-MoRSE descriptors-signal 09 / weighted by mass. \\
\hline 18 & TIE & Topological indices-E-state topological parameter. \\
\hline 19 & Dipole z & An electric dipole is located along the $z$ axis. \\
\hline 20 & Mor26e & 3D-MoRSE descriptors-signal 26 / weighted by Sanderson electronegativity. \\
\hline 21 & $\mathrm{ISH}$ & GETAWAY descriptors-standardized information content on the leverage equality. \\
\hline 22 & MATS1p & Moran autocorrelation - lag 1 / weighted by atomic polarizabilities \\
\hline 23 & MATS8e & Moran Autocorrelation-lag 8/weighted by atomic Sanderson electronegativities. \\
\hline 24 & $\mathrm{Ku}$ & K global shape index / unweighted \\
\hline 25 & $\mathrm{P} 2 \mathrm{~m}$ & 2nd component shape directional WHIM index / weighted by atomic masses \\
\hline
\end{tabular}
an $\mathrm{H}$-depleted molecular graph. They involve one or more structural features of the molecule such as the size,

Table 4 Brief description of the descriptors in five models 
Table 5 Experimental $\mathrm{plC}_{50}$ and MLR and GA-PLS predicted $\mathrm{plC}_{50}$

\begin{tabular}{|c|c|c|c|c|c|c|c|}
\hline NO. & Experimental $\mathrm{plC}_{50}$ & $\begin{array}{l}\text { MLR } \\
\mathrm{plC}_{50}\end{array}$ & $\begin{array}{l}\text { GA-PLS } \\
\mathrm{plC}_{50}\end{array}$ & NO. & Experimental $\mathrm{pl} \mathrm{C}_{50}$ & $\begin{array}{l}\text { MLR } \\
\mathrm{plC}_{50}\end{array}$ & $\begin{array}{l}\text { GA-PLS } \\
\mathrm{plC}_{50}\end{array}$ \\
\hline 15 & 3.82 & 3.64 & 3.89 & 53 & 4.66 & 4.59 & 3.96 \\
\hline 16 & 3.74 & 3.71 & 4.13 & 54 & 4.62 & 4.65 & 4.57 \\
\hline 17 & 3.79 & 4.13 & 3.52 & 55 & 4.70 & 4.84 & 4.70 \\
\hline 18 & 3.89 & 4.69 & 3.57 & 56 & 4.72 & 4.68 & 4.79 \\
\hline 19 & 4.13 & 3.84 & 3.78 & 57 & 4.08 & 4.48 & 4.41 \\
\hline 20 & 4.43 & 4.25 & 4.29 & 58 & 4.66 & 4.39 & 4.47 \\
\hline 21 & 4.07 & 3.91 & 4.15 & 59 & 3.60 & 4.38 & 3.99 \\
\hline 22 & 3.78 & 4.06 & 4.06 & 61 & 4.40 & 4.41 & 4.30 \\
\hline 24 & 3.80 & 3.67 & 3.74 & 62 & 5.00 & 4.82 & 4.61 \\
\hline 26 & 4.26 & 4.32 & 5.39 & 64 & 3.59 & 4.75 & 3.95 \\
\hline 27 & 4.39 & 4.55 & 4.41 & 65 & 4.32 & 4.72 & 4.15 \\
\hline 28 & 3.72 & 3.70 & 3.81 & 66 & 4.21 & 4.14 & 4.30 \\
\hline 29 & 3.58 & 3.90 & 3.73 & 67 & 4.48 & 4.84 & 4.90 \\
\hline 30 & 3.62 & 3.60 & 3.68 & 68 & 4.47 & 4.62 & 4.61 \\
\hline 31 & 4.62 & 4.44 & 4.33 & 69 & 4.70 & 4.64 & 4.73 \\
\hline 32 & 4.52 & 4.37 & 4.61 & 70 & 4.82 & 5.04 & 4.44 \\
\hline 44 & 4.41 & 4.54 & 4.18 & 73 & 4.40 & 4.26 & 4.39 \\
\hline 45 & 4.85 & 4.60 & 4.42 & $75 a$ & 4.90 & 4.72 & 4.69 \\
\hline 46 & 4.58 & 4.14 & 4.52 & $75 d$ & 4.82 & 4.29 & 4.61 \\
\hline 47 & 4.47 & 4.54 & 4.62 & $79 b$ & 3.67 & 3.72 & 4.55 \\
\hline 48 & 4.47 & 4.72 & 4.34 & $79 c$ & 3.92 & 3.92 & 4.11 \\
\hline 49 & 4.15 & 4.08 & 4.68 & $81 a$ & 3.64 & 3.41 & 3.54 \\
\hline 50 & 4.62 & 4.60 & 4.30 & $81 b$ & 3.37 & 3.49 & 3.74 \\
\hline 51 & 4.49 & 4.52 & 4.53 & $81 c$ & 3.21 & 3.28 & 4.42 \\
\hline 52 & 4.49 & 5.36 & 4.56 & $81 d$ & 2.80 & 3.26 & 4.42 \\
\hline
\end{tabular}

shape, symmetry, and branching and can also codify chemical information about atom type and bond multiplicity. 3D-MoRSE descriptors, such as Mor26p, illustrate three-dimensional coordination of the different atoms in the molecule. Geometry, topology, and atomweights assembly (GETAWAY) descriptors, such as HATS4u, have been proposed as chemical structure descriptors.
TIE and dipole $\mathrm{z}$ display positive signs, which indicates the $\mathrm{pIC}_{50}$ is straight related to these descriptors. Topographic indices such as TIE establish a special subset of geometrical descriptors, being computed on the graph illustration of molecules but using the geometric distances between atoms instead of the topological distances [30].

The general model has a $\mathrm{Q}_{\mathrm{LOO}}^{2}$ equal to 0.710; hence, the predicted model can construct over $71 \%$ of variances
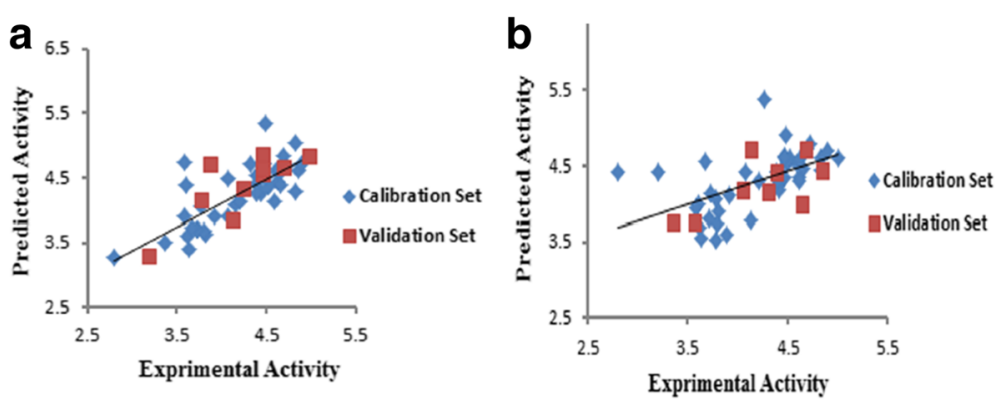

Fig. 4 a Plot of predicted $\mathrm{plC}_{50}$ versus the experimental values for MLR model, $\mathbf{b}$ GA-PLS model 
Table $6 \mathrm{R}^{2}$ and $\mathrm{Q}_{\mathrm{L}}^{2}$ oo values after ten $\mathrm{Y}$-randomization tests in MLR and GA-PLS

\begin{tabular}{llllll}
\hline Iteration & \multicolumn{2}{l}{ MLR } & & \multicolumn{2}{l}{ GA-PLS } \\
\cline { 2 - 3 } \cline { 5 - 6 } & $R^{2}$ & $Q_{\text {LOO }}^{2}$ & & $R^{2}$ & $Q_{\text {LOO }}^{2}$ \\
\hline 1 & 0.158 & 0.021 & & 0.069 & 0.081 \\
2 & 0.034 & 0.162 & & 0.096 & 0.022 \\
3 & 0.186 & 0.025 & 0.140 & 0.004 \\
4 & 0.134 & 0.013 & 0.080 & 0.082 \\
5 & 0.085 & 0.006 & 0.115 & 0.001 \\
6 & 0.102 & 0.001 & 0105 & 0.016 \\
7 & 0.119 & 0.001 & 0.182 & 0.018 \\
8 & 0.082 & 0.032 & 0.072 & 0.054 \\
9 & 0.075 & 0.047 & 0.185 & 0.004 \\
10 & 0.091 & 0.004 & 0.082 & 0.024 \\
\hline
\end{tabular}

in the inhibitory activity. The proposed values of $\mathrm{pIC}_{50}$, which were calculated for all the molecules by the MLR equation, along with the experimental $\mathrm{pIC}_{50}$ are listed in Table 5 and the predicted values of $\mathrm{pIC}_{50}$ are plotted against the experimental values in Fig. 4a.

The robustness of the general model was evaluated by the Y-randomization test and 10 models were created. In a suitable MLR model, the values of $R^{2}$ and $Q_{L O O}^{2}$ are lower than the original MLR model. The lower $R^{2}$ and $\mathrm{Q}_{\mathrm{LOO}}^{2}$ values are shown in Table 6.

\section{Genetic algorithm partial least squares (GA-PLS)}

In addition to MLR method, the stepwise regression, a variable selection method, such as genetic algorithm, was performed. In genetic algorithm, if its related descriptor is comprised, a gene takes a value of 1 in the subset; otherwise, it receipts a value of zero. The number of genes is corresponding to the number of descriptors.

In GA-PLS study, the total number of descriptors for each molecule attained 117 and the highest fitness was selected as the proposed model. The intended model was tested by leave-n-out cross-validation [31]. A leave3-out cross-validation was generated and $\mathrm{Q}_{\mathrm{LTO}}^{2}$ value of 0.834 could be established.
The eventuated model with higher cross-validation statistics is shown in the following equation and the predicted values of $\mathrm{pIC}_{50}$ are reported in Table 5 and plotted against the experimental values in Fig. $4 \mathrm{~b}$.

$$
\begin{aligned}
\mathrm{pIC} 50= & 9.018( \pm 2.799)-114.521( \pm 30.435) \mathrm{X} 5 \mathrm{~A} \\
& -1.406( \pm 0.266) \text { GATS4e }-1.586( \pm 0.991) \mathrm{E} 3 \mathrm{u} \\
& -2.615( \pm 0.649) \text { MATS7e }+38.705( \pm 8.531) \mathrm{G} 1 \mathrm{u} \\
& +0.048( \pm 0.014) \text { RDF075m }
\end{aligned}
$$

$\left(\mathrm{N}=41, \mathrm{R}^{2} \mathrm{C}=0.755, \mathrm{~S} . \mathrm{E}=0.249, \mathrm{Q}^{2}{ }_{\mathrm{LOO}}=0.653, \mathrm{RMSCV}=0.266\right)$

In this equation, X5A descriptor, like MLR equation, has a minus and also has a main effect on 3, 4isoxazolediamide Hsp90 inhibitors. GATS4e, E3u, and MATS7e also have minuses. Unlike these, G1u and RDF075m (WHIM and the radial distribution function (RDF) descriptors) have a positive efficacy on GA-PLS.

The created model in GA-PLS was evaluated by Yrandomization test. The $\mathrm{R}^{2}$ and $\mathrm{Q}_{\mathrm{LOO}}^{2}$ values of the ten created models were lower than the original GA-PLS model, as shown in Table 6.

\section{Applicability domain of the model}

A QSAR model is applied to monitor new compounds when its domain of application has been determined [29]. The divination may be supposed valid for only those compounds which fall into this domain [15]. Therefore standardized residuals of the activity were calculated and plotted against leverage values (h). The value of leverage was computed for every compound. Values are evermore between 0 and 1 . A value of 1 indicates very poor prediction, and a value of 0 is indicative of perfect prediction and is not usually available. The lower the value is, the higher the assurance in the prediction. Warning leverage $\left(h^{*}\right)$ is another standard for description of the results and is commonly stabilized at $3(\mathrm{k}+1) / \mathrm{n}$, where $\mathrm{k}$ is the number of model parameters and $\mathrm{n}$ is the number of calibration set [15]. Obtained leverage for calibration set is used to define the compounds which affect the model and, in terms of validation set, used to determine the applicability
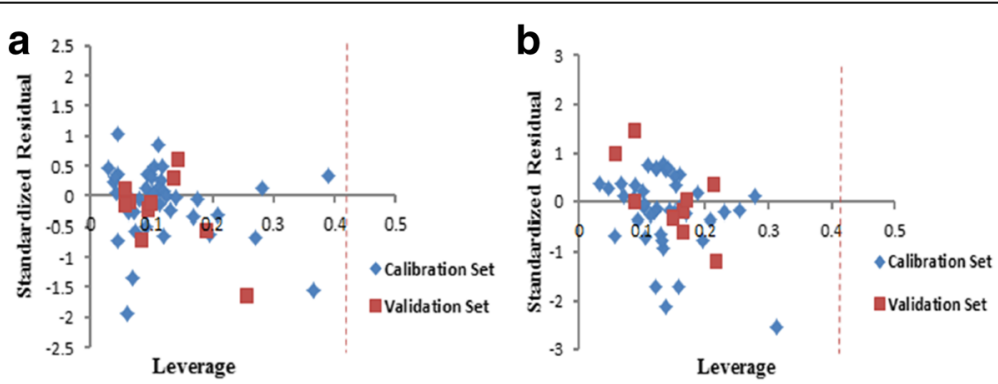

Fig. 5 a William's plot of generated MLR model, $\mathbf{b}$ GA-PLS model 


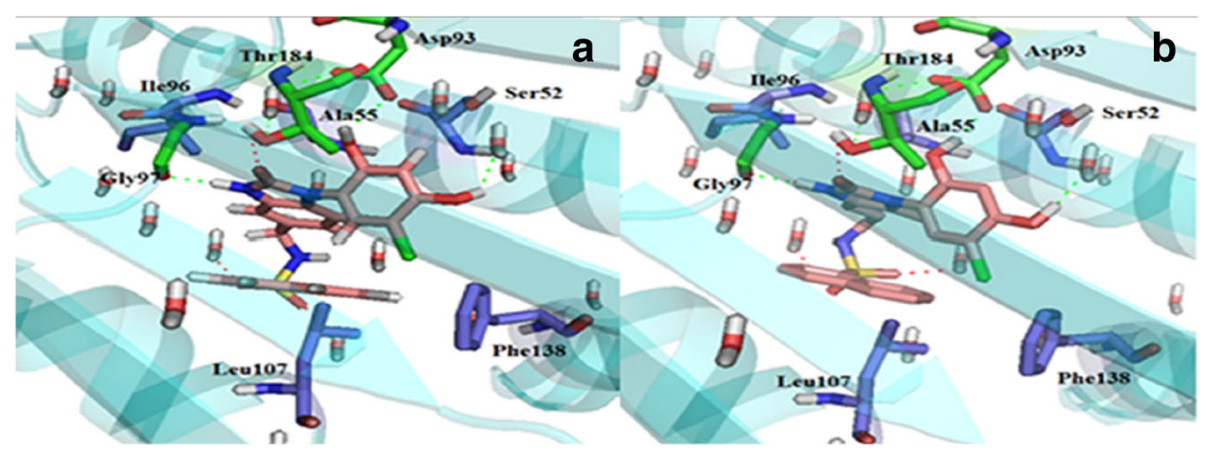

Fig. 6 a The position of ligand in X-ray crystallography, b The position of ligand after redocking

domain of the model. William's plot for the advanced models in MLR and GA-PLS is revealed in Fig. 5.

Rejoinder outliers are compounds that have standard residual points higher than \pm 2.5 and \pm 3.0 standard deviation units for MLR and GA-PLS respectively and also a leverage value higher than the warning leverage, which is 0.42 . Figure 5 shows that all the considered molecules in calibration and validation set lie with a high degree of assurance in the application domain of the developed models in both methods.

\section{Molecular docking}

ATP is Hsp90 substrate and its active site includes mixed hydrophobic, polar and charged amino acids. These residues include Leu48, Asn51, Asp54, Ala55, Lys58, Ile91, Asp93, Ile96, Gly97, Met98, Asn106, Leu107, Lys112, Gly135, Phe138, Val150, Thr184, and Val186. While the pocket becomes increasingly hydrophobic toward the bottom, one charged residue and one polar residue are retained as Asp93 and Thr184 respectively [32]. The adenine ring in ATP sits at the bottom of the pocket and its N6 group form direct hydrogen bonds with Asp93 (Asp79 in yeast Hsp83), and water-mediated hydrogen bonds with the Ser52 and Leu48. Also, Glu47 (Glu33 in yeast Hsp83) gets involved in Hsp90 ATPase activity [33, 34].
A crystallography structure of 3OWD was chosen for the structure-based drug design. A validation of docking procedure was done by the extraction of the ligand from $\mathrm{X}$-ray complex and redocking it. A .dlg file was created. A cluster root-mean-square deviation (RMSD) at less than $2 \AA$ whose initial coordinates of the ligand were used as the reference structure was observed. The obtained results show that the docked ligand was located in the active site of Hsp90 (Fig. 6).

As previously mentioned, Asp93 is one of the important residues in Hsp90 ATPase. The pathway into Asp93 is a large cavity, and in its crater Asn51, Ala55, Lys58, Gly97, Met98, Asp102, Asn106 and Phe138 lie. Asp93 and Thr184 stay on the bottom of the pocket (Fig. 7a). Other pathways into Asp93 and the involved residues were obtained by CAVAER 3.0.1 software [27]. Likely pathways were computed by assigning maximum probe radius to 0.9 Á, shell depth to 4 , and clustering threshold to 3.5 Á. Four tunnels were obtained, which are depicted in Fig. 7b. As can be seen, all of the tunnels stay at the back of the cavity.All residues in the depth of the tunnel included Ile49, Ser50, Ser52, Ser53, His77, Ile78, Leu80, Ile91, Va192, Asp93, Val207, His210, Gln212, Phe213, Ile214, Tyr216, Pro217, Ile218, Thr219 and Leu220.

After the validation of the docking protocol and finding entrance tunnels, the 3D structures of 3,4-isoxazolediamide
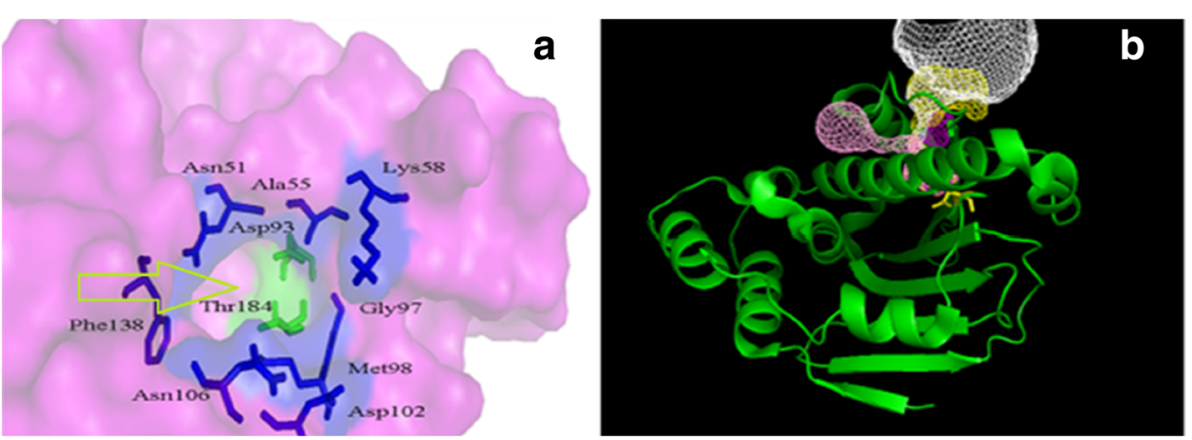

Fig. 7 a Main cavity in Hsp90, b Four entrance tunnels in back of main cavity 
Table 7 Interactions between the docked 3, 4-isoxazolediamide derivatives and Hsp90 binding site residues

\begin{tabular}{|c|c|c|c|c|c|}
\hline \multirow[t]{2}{*}{ Comp. } & \multirow[t]{2}{*}{$\begin{array}{l}1 C_{50} \\
(\mu \mathrm{M})\end{array}$} & \multirow[t]{2}{*}{$\begin{array}{l}\Delta G_{\text {binding }} \\
(\mathrm{kcal} / \mathrm{mol})\end{array}$} & \multicolumn{2}{|c|}{$\begin{array}{l}\text { Hydrogen bonds between atoms of } \\
\text { compounds and amino acids }\end{array}$} & \multirow[t]{2}{*}{ Hydrophobic amino acids } \\
\hline & & & Atom of comp. & Amino acid (Distance $\AA$ ) & \\
\hline \multirow[t]{2}{*}{15} & \multirow[t]{2}{*}{0.153} & \multirow[t]{2}{*}{-2.08} & Ortho- $\mathrm{OH}$ resorcinol ring & Asp93(1.974) & \multirow{2}{*}{$\begin{array}{l}\text { Lys58, Gly135, Ala55, Ile96, Asn106, Met98, Gly97, Asn51, Ser52, } \\
\text { Leu107, Phe138, Leu48, Thr184 }\end{array}$} \\
\hline & & & Para- $\mathrm{OH}$ resorcinol ring & $\mathrm{HOH}^{\mathrm{a}}(1.828)$ & \\
\hline \multirow[t]{2}{*}{16} & \multirow[t]{2}{*}{0.184} & \multirow[t]{2}{*}{-1.90} & Ortho- $\mathrm{OH}$ resorcinol ring & Asp93(1.910) & \multirow{2}{*}{$\begin{array}{l}\text { Lys58, Gly135, Ala55, lle96, Asn106, Met98, Gly97, Asn51, Ser52, } \\
\text { Leu107, Phe138, Leu48,Thr184, Val186 }\end{array}$} \\
\hline & & & Para- $\mathrm{OH}$ resorcinol ring & $\mathrm{HOH}(1.863)$ & \\
\hline \multirow[t]{5}{*}{18} & \multirow[t]{5}{*}{0.130} & \multirow[t]{5}{*}{-2.15} & Para- $\mathrm{OH}$ resorcinol ring & Lys58(2.164) & \multirow{5}{*}{$\begin{array}{l}\text { Thr152, lle96, Ala55, Ser52, Val186, Val150, Leu107, Tyr139, } \\
\text { Val136, lle26, Asp93 }\end{array}$} \\
\hline & & & & $\mathrm{HOH}(2.153)$ & \\
\hline & & & Ortho- $\mathrm{OH}$ resorcinol ring & Asn106(2.155) & \\
\hline & & & O atom-isoxazole & $\mathrm{HOH}(2.632)$ & \\
\hline & & & $\mathrm{NH}$ - isoxazole & $\mathrm{HOH}(2.373)$ & \\
\hline \multirow[t]{3}{*}{19} & \multirow[t]{3}{*}{0.074} & \multirow[t]{3}{*}{-2.24} & \multirow[t]{2}{*}{ Para- $\mathrm{OH}$ resorcinol ring } & Asp93(1.887) & \multirow{3}{*}{$\begin{array}{l}\text { Lys58, Gly135, Ala55, lle96, Asn106, Met98, Gly97, Asn51, Ser52, } \\
\text { Leu107, Phe138, Leu48, Thr184, Val186 }\end{array}$} \\
\hline & & & & $\mathrm{HOH}(2.085)$ & \\
\hline & & & O atom- isoxazole & $\mathrm{HOH}(2.153)$ & \\
\hline \multirow[t]{3}{*}{20} & \multirow[t]{3}{*}{0.037} & -2.85 & Ortho- OH-resorcinol ring & Asp93(1.710) & Leu48, Asn51, Asp54, Ser52, Ala55,Lys58, Ile96, Met98, Leu107, \\
\hline & & & Para- OH-resorcinol ring & $\mathrm{HOH}(1.919)$ & \\
\hline & & & $\mathrm{NH}$ - isoxazole & Gly97(2.373) & \\
\hline 21 & 0.085 & -2.23 & Para- OH-resorcinol ring & Asp93(2.044) & Leu48, Gly97, Asp54, Ser52, Ala55,Lys58, Ile96, Met98, Asn106, \\
\hline & & & Ortho- OH-resorcinol ring & Asn51(1.970) & Leu10/, Lys T12, Gly135, Phe138, I hr184, vall86 \\
\hline 22 & 0.167 & -1.93 & Ortho- OH-resorcinol ring & Asp93(1.719) & Leu48, Asn51, Asp54, Ser52, Ala55, Lys58, Ile96, Met98, Leu107, \\
\hline & & & Para- OH-resorcinol ring & $\mathrm{HOH}(2.085)$ & \\
\hline & & & $\mathrm{NH}$ - isoxazole & Gly97(2.287) & \\
\hline 24 & 0.160 & -1.98 & Para- $\mathrm{OH}$ resorcinol ring & Asp93(1.819) & Leu48, Gly97, Asp54, Ser52, Ala55, Asn51, Ile96, Met98, Asn106, \\
\hline & & & & $\mathrm{HOH}(2.115)$ & \\
\hline & & & O atom- isoxazole & $\mathrm{HOH}(2.200)$ & \\
\hline & & & F atom-terminal ethyl & $\mathrm{HOH}(1.813)$ & \\
\hline & & & O atom-methoxy & Lys58(2.105) & \\
\hline 26 & 0.055 & -2.58 & Para- OH-resorcinol ring & $\operatorname{Asp93(2.225)}$ & Leu48, Asp54, Ser52, Ala55, Asn51, Ile96, Met98, Asn106, Leu107, \\
\hline & & & Ortho- OH-resorcinol ring & Gly97(2.064) & \\
\hline & & & O atom-terminal ethyl & Lys58(1.812) & \\
\hline 27 & 0.041 & -2.59 & Para- $\mathrm{OH}$ resorcinol ring & $\mathrm{HOH}(2.111)$ & Leu48, Gly97, Asp54, Ser52, Ala55,Lys58, Ile96, Met98, Asn51, \\
\hline & & & O atom-terminal ethyl & $\mathrm{HOH}(2.459)$ & Gly95, Asp93, Leu10/, Lys112, Gly135, Phe138, Thr184, Val186 \\
\hline & & & $\mathrm{NH}$ - terminal amid & Asn106(2.124) & \\
\hline 28 & 0.190 & -1.92 & Para- $\mathrm{OH}$ resorcinol ring & Thr184(1.724) & Asp93, Asp54, Ser52, Ala55, Asn51, Ile96, Met98, Leu107, Phe138, \\
\hline & & & Ortho- OH-resorcinol ring & Gly97(2.262) & \\
\hline & & & $\mathrm{NH}$ - isoxazole & $\mathrm{HOH}(2.022)$ & \\
\hline & & & $\mathrm{NH}$ - isoxazole & $\mathrm{HOH}(1.113)$ & \\
\hline & & & $\mathrm{NH}$ - terminal amid & Asn106(2.492) & \\
\hline 30 & 0.240 & -1.85 & Para- OH-resorcinol & Ala55(1.640) & Asp93, Asp54, Ser52, Lys58, Asn51, Gly97, Met98, Asn106, \\
\hline & & & Ortho- OH-resorcinol & $\mathrm{HOH}(2.397)$ & \\
\hline 46 & 0.026 & -3.02 & Para- OH-resorcinol ring & Asp93(2.106) & Thr152, Gly97,lle96, Val186, Ala55, Asp102, Leu107, Tyr132, \\
\hline & & & Ortho- OH-resorcinol ring & Asn51(2.058) & \\
\hline & & & O atom- isoxazole & Asn51(2.805) & \\
\hline & & & $\mathrm{NH}$ - isoxazole & $\mathrm{HOH}(2.433)$ & \\
\hline & & & O atom-methoxy & Lys58(2.933) & \\
\hline
\end{tabular}


Table 7 Interactions between the docked 3, 4-isoxazolediamide derivatives and Hsp90 binding site residues (Continued)

\begin{tabular}{|c|c|c|c|c|c|}
\hline \multirow[t]{5}{*}{57} & \multirow[t]{5}{*}{0.084} & \multirow[t]{5}{*}{-2.31} & Ortho- OH-resorcinol ring & Asp93(1.887) & \multirow{5}{*}{$\begin{array}{l}\text { Leu48, Asn51, Asp54, Ser52, Ala55, Lys58, lle96, Met98, Leu107, } \\
\text { Phe138, Thr184, Val186 }\end{array}$} \\
\hline & & & Para- OH-resorcinol ring & $\mathrm{HOH}(1.800)$ & \\
\hline & & & $S$ atom-terminal amid & $\mathrm{HOH}(1.129)$ & \\
\hline & & & O atom-terminal ethyl & $\mathrm{HOH}(1.830)$ & \\
\hline & & & $\mathrm{NH}$ - isoxazole & Gly97(2.314) & \\
\hline \multirow[t]{3}{*}{58} & \multirow[t]{3}{*}{0.022} & \multirow[t]{3}{*}{-3.40} & Ortho- OH-resorcinol ring & Asp93(1.799) & \multirow{3}{*}{$\begin{array}{l}\text { Leu48, Asn51, Ser52, Ala55, Lys58, lle96, Met98, Asn106, Leu107, } \\
\text { Phe138, Gly135, Thr184, Val186, Val150 }\end{array}$} \\
\hline & & & Para- OH-resorcinol ring & $\mathrm{HOH}(1.773)$ & \\
\hline & & & $\mathrm{NH}$ - isoxazole & Gly97(2.375) & \\
\hline \multirow[t]{2}{*}{59} & \multirow[t]{2}{*}{0.250} & \multirow[t]{2}{*}{-1.84} & Para- OH-resorcinol ring & Thr184(1.814) & \multirow{2}{*}{$\begin{array}{l}\text { Asp93, Leu48, Asn51, Ser52, Ala55, Lys58, lle96, Met98, Gly97, } \\
\text { Asn106, Leu107, Gly135 }\end{array}$} \\
\hline & & & O atom-terminal ethyl & $\mathrm{HOH}(2.385)$ & \\
\hline \multirow[t]{4}{*}{61} & \multirow[t]{4}{*}{0.040} & \multirow[t]{4}{*}{-2.68} & Ortho- OH-resorcinol ring & Asp93(1.832) & \multirow{4}{*}{$\begin{array}{l}\text { Leu48, Asn51, Ser52, Ala55, Lys58, lle96, Met98, Asn106, Leu107, } \\
\text { Phe138, Gly135, Thr184, Val186, Val150 }\end{array}$} \\
\hline & & & Para- OH-resorcinol ring & $\mathrm{HOH}(1.816)$ & \\
\hline & & & $\mathrm{NH}$ - isoxazole & Gly97(2.328) & \\
\hline & & & NH-thiazole & $\mathrm{HOH}(2.308)$ & \\
\hline \multirow[t]{5}{*}{64} & \multirow[t]{5}{*}{0.260} & \multirow[t]{5}{*}{-1.82} & Para- OH-resorcinol ring & Lys58(2.045) & \multirow{5}{*}{$\begin{array}{l}\text { Asp93, Asn51, Ser52, Ala55, Asp54, lle96, Met98, Gly97, Phe138, } \\
\text { Gly135, Val136, Tyr139, Asn106, Leu107, Thr184, Val186 }\end{array}$} \\
\hline & & & & $\mathrm{HOH}(2.032)$ & \\
\hline & & & Ortho- OH-resorcinol ring & Asn106(2.134) & \\
\hline & & & O atom- isoxazole & $\mathrm{HOH}(2.449)$ & \\
\hline & & & NH-isoxazole & $\mathrm{HOH}(2.340)$ & \\
\hline 65 & 0.048 & -2.62 & O atom- isoxazole & $\mathrm{HOH}(2.733)$ & $\begin{array}{l}\text { Asp93, Asn51, Ser52, Ala55, Lys58, lle96, Met98, Gly97, Phe138, } \\
\text { Gly135, Val136, Tyr139, Asn106, Leu107, Thr184, Val186 }\end{array}$ \\
\hline \multirow[t]{6}{*}{66} & \multirow[t]{6}{*}{0.062} & \multirow[t]{6}{*}{-2.46} & Para- OH-resorcinol ring & Lys58(2.144) & \multirow{6}{*}{$\begin{array}{l}\text { Asp93, Asn51, Ser52, Asp54, Ala55, Ile96, Met98, Gly97, Phe138, } \\
\text { Gly135, Val136, Tyr139, Gly137, Leu107, Thr184, Val186 }\end{array}$} \\
\hline & & & & $\mathrm{HOH}(1.937)$ & \\
\hline & & & Ortho- OH-resorcinol ring & Asn106(2.074) & \\
\hline & & & O atom- isoxazole & $\mathrm{HOH}(2.477)$ & \\
\hline & & & $\mathrm{NH}$ - isoxazole & $\mathrm{HOH}(2.218)$ & \\
\hline & & & $\mathrm{NH}$-terminal ethyl & Asn106(1.829) & \\
\hline 69 & 0.020 & -3.50 & Para- OH-resorcinol ring & $\mathrm{HOH}(2.022)$ & Asn51, Ser52, Asp54, Ala55, Lys58, lle96, Met98, Phe138, Gly135, \\
\hline & & & Ortho- OH-resorcinol ring & Asp93(1.909) & Vall36, lyri39, Asn 106, Leulu/, Inrl84, vall80 \\
\hline & & & $S$ atom-terminal amid & $\mathrm{HOH}(1.969)$ & \\
\hline & & & $\mathrm{NH}$ - isoxazole & Gly97(2.365) & \\
\hline 73 & 0.040 & -2.80 & Ortho- OH-resorcinol ring & Asp93(2.067) & Asn51, Ser52, Asp54, Ala55, Lys58, lle96, Gly97, Phe138, Gly135, \\
\hline & & & Para- OH-resorcinol ring & $\mathrm{HOH}(1.968)$ & \\
\hline & & & $\mathrm{NH}$ - isoxazole & Met98(2.082) & \\
\hline & & & O atom-terminal ethyl & $\mathrm{HOH}(2.277)$ & \\
\hline $81 \mathrm{a}$ & 0.230 & -1.88 & Para- OH-resorcinol ring & $\operatorname{Asp93(2.250)}$ & Asn51, Ser52, Asp54, Ala55, Ile96, Met98, Asp106, Thr184 \\
\hline & & & Ortho- OH-resorcinol ring & Gly97(1.942) & \\
\hline & & & O atom-terminal ethyl & Lys58(1.888) & \\
\hline $81 b$ & 0.430 & -1.76 & Ortho- OH-resorcinol ring & Asp93(1.704) & Lys58, Ser52, Asp54, Ala55, Ile96, Met98, Gly97, Asp106, Leu107, \\
\hline & & & Para- OH-resorcinol ring & $\mathrm{HOH}(2.099)$ & Intro4, vallo \\
\hline & & & $\mathrm{NH}$ - terminal methoxy & Asn51(2.160) & \\
\hline $81 \mathrm{c}$ & 0.620 & -1.65 & Ortho- OH-resorcinol ring & Asp93(1.724) & Lys58, Ser52, Asp54, Ala55, Ile96, Met98, Asp106, Leu107, Thr184, \\
\hline & & & Para- OH-resorcinol ring & $\mathrm{HOH}(1.860)$ & valiob, Phels8 \\
\hline & & & $\mathrm{NH}$ - isoxazole & Gly97(2.305) & \\
\hline & & & $\mathrm{NH}$-cyclohexane & Asn51(2.153) & \\
\hline
\end{tabular}



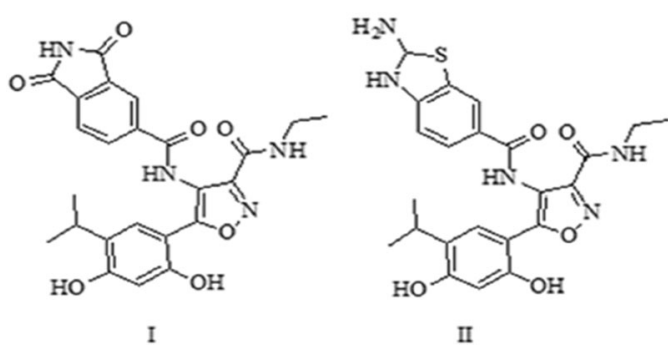

Fig. 8 The predicted novel inhibitors based on QSAR model and docking<smiles>CCNC(=O)c1noc(-c2cc(C(C)C)c(O)cc2O)c1C(=O)c1ccc2ccc(=O)oc2c1</smiles>

derivatives (25 compounds) were docked into crystallography structure 3OWD. In .dlg files, the structures were ranked by binding energy and clusters. All of the compounds were perched into the cavity of the active site (Table 7). The compounds were divided into three groups.

\section{Group A (compounds 15-24)}

In this Group, the meta-position of resorcinol ring was substituted by a large chloro group. So, when $R_{1}$ group was small, for example like the $\mathrm{CH}_{3}$ group, hydroxyl groups in resorcinol ring could interact well with Asp93. On the other hand, large groups in $R_{1}$ such as 1,2,3-trimethoxybenzene groups, due to steric hindrance, changed steric orientation of hydroxyl groups in resorcinol and hydroxyl groups could interact with Asp93 by a water-bridge hydrogen bond. According to what was mentioned above, compound 20 was the best inhibitor in this group. Compound 18 had a 1,2,3-trimethoxybenzene group, but trimethoxy groups created a better hydrogen bond with Lys112 than methoxy group.

\section{Group B (compounds 26-73)}

Meta position of resorcinol ring was occupied by an isopropyl in this group. According to the biological assay, the lowest $\mathrm{IC}_{50}$ was related to compound 69 and it was the strongest compound that docking analysis revealed.
The ortho-hydroxyl group of resorcinol ring with Asp93, para-hydroxyl with Ser52 by a water-bridge, and nitrogen atom of isoxazole with Gly97 was created the hydrogen bonds. Steric orientation in compound 58 was observed to be similar to that of 69 . But, 69 was stronger than 58 , because sulfur atom of $R_{1}$ group in 69 created a hydrogen bond with Phe138 and Asn51 by a water-bridge. In compound 46, para-hydroxyl made a hydrogen bond with Asp93 and $\mathrm{O}$ atom in methoxy group could create $\mathrm{H}$ bond with Lys58. The steric orientation in cyclohexane made compound 28 , and 30 could not directly create a hydrogen bond with Asp93. The connected $\mathrm{R}_{1}$ group to carbonyl was isoxazole in 73 and 59 but 73 was a stronger inhibitor than 59. The connected benzene group to this isoxazole changed the steric orientation in resorcinol and could not directly make a hydrogen bond with Asp93. Unlike Group A, in this group the compounds with smaller $\mathrm{R}_{1}$ substituent were not potent inhibitors.

\section{Group C (compounds 81a-81c)}

In this group, on meta-position of resorcinol ring was placed a large chloro group and $R_{1}$ was connected to NH. 81a was stronger than both $81 \mathrm{~b}$ and $81 \mathrm{c}$. Thiophene group was better than either methoxybenzen or cyclohexane. The same as Group A, the compounds with small $R_{1}$ groups were stronger inhibitors.
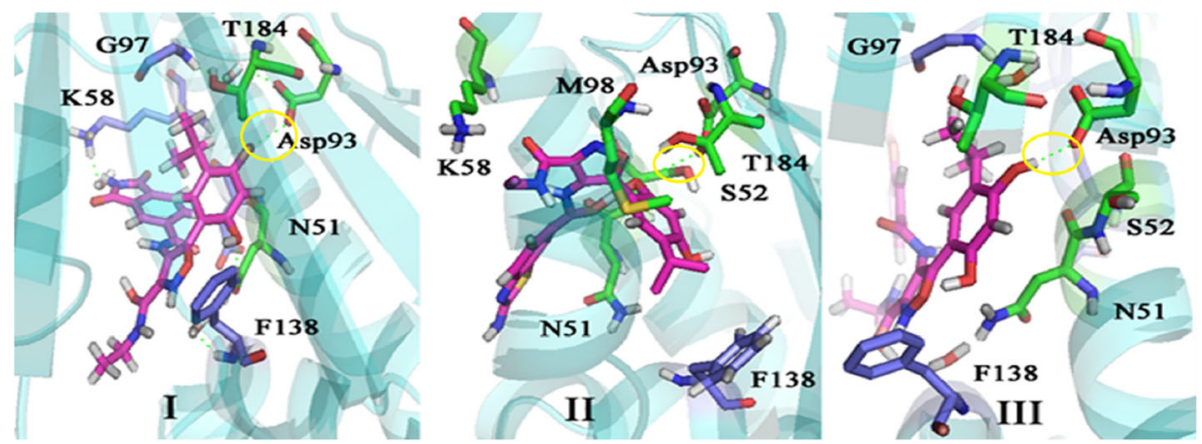

Fig. 9 Orientation and main interaction between three predicted compounds and Hsp90 

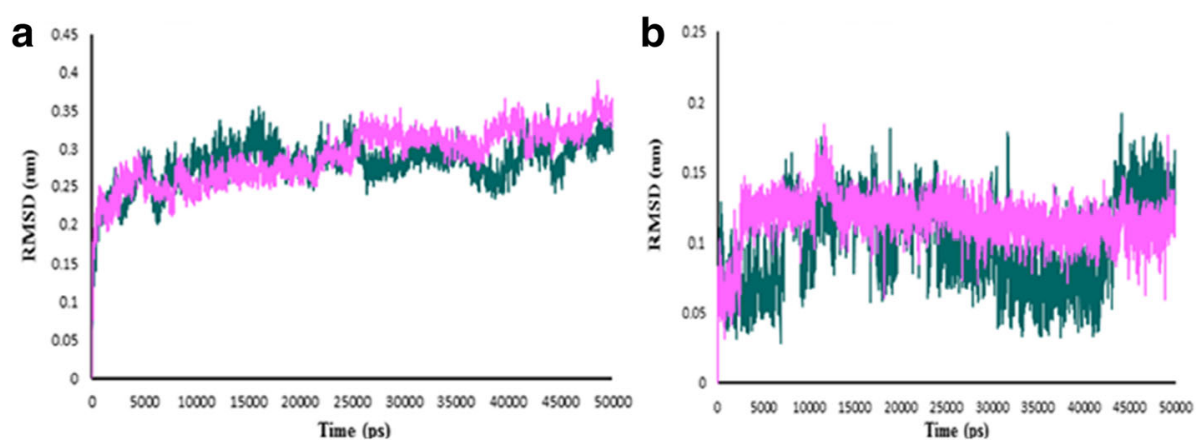

Fig. 10 The RMSD profile. a Hsp90 backbone in complex with compound 69 (violet), predicted ligand II (green). b Compound 69 (violet), predicted ligand II (green) as a function of simulation time

\section{Predicted ligands and molecular dynamic simulation}

Three novel compounds (Fig. 8) were predicted with the modification of compounds based on results of QSAR model and molecular docking.

Docking study was performed on the predicted compounds. In these compounds, similar to previously evaluated compound, the hydroxyl groups of resorcinol ring interacted with Asp93 (Fig. 9). The binding energy of compound II was the lowest $(-8.20 \mathrm{kcal} / \mathrm{mol})$.

To ensure the stability of the new ligand II in the active site of protein, the MD simulation was carried out and its interaction modes with compound 69 in Hsp90 active site was also compared. The best conformation of docking was chosen to perform 50 ns MD simulation. The time-dependent behavior of MD trajectories were analyzed including root mean square deviation (RMSD) for all backbone atoms and ligands, average fluctuations of the residues (RMSF) and gyration radius (Rg) for all backbone atoms.

The RMSD of backbone atoms was figured to assessment the conformational stability of the protein during the simulation. The RMSD of backbone atoms between complexes of Hsp90-ligand 69 and Hsp90-predicted ligand II was measured with a 10 ps time interval. As illustrated in Fig. 10a, the RMSD profile in the two complexes was almost the same in the first 10 ns. Variations of RMSD were not very considerable, which denote the stability of both complexes. The ligand RMSD profile in Fig. 10b shows that the ligand 69 after 3 ns and predicted ligand II after $8 \mathrm{~ns}$ become stable. The RMSD variations were almost $0.1 \mathrm{~nm}$ in ligand 69 and predicted ligand II, it can be observed that both of the ligands were also fit in the active site and stabilized. The protein compactness was evaluated by the gyration radius $(\mathrm{Rg})$. The $\mathrm{Rg}$ plot is shown in Fig. 11. In the first 27 ns and the last $10 \mathrm{~ns}$, the $\mathrm{Rg}$ values of ligand 69 and the predicted ligand II were superimposed and the conjunction of both complexes was conserved during the simulation.
The variations of protein flexibility were identified by the root mean square fluctuation (RMSF) of backbone residues. As shown in Fig. 12, in residues 45-61 and $89-107$, the fluctuation of predicted ligand II was lower than compound 69 which disclose that predicted ligand II was more stable than compound 69 in these parts. This can be attributed to the attendance of these residues in the active site of protein. In residues 61-70 the fluctuation was high, which indicates that these parts of the protein were more unstable than other parts during the MD simulation, especially in the predicted ligand II.

To discover the conformations and interactions of the predicted ligand II and compound 69 during simulation, $3 \mathrm{D}$ plots of the different times of simulation were shown (Fig. 13). Figure 13 shows the comparison between the compound 69 and predicted ligand II in the active site of Hsp90 during 0, 25 and 50 ns of the simulation (a, b columns). In all simulation times, the resorcinol hydroxyl group of both compounds formed hydrogen bond with Asp93. On other side of both compounds perched

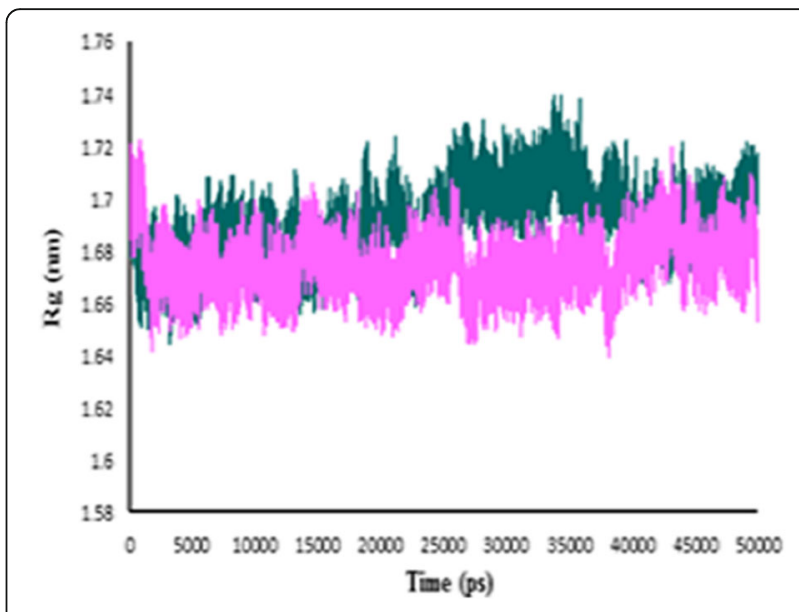

Fig. 11 The gyration radius plot of backbone. Compound 69 (violet), predicted ligand II (green) 


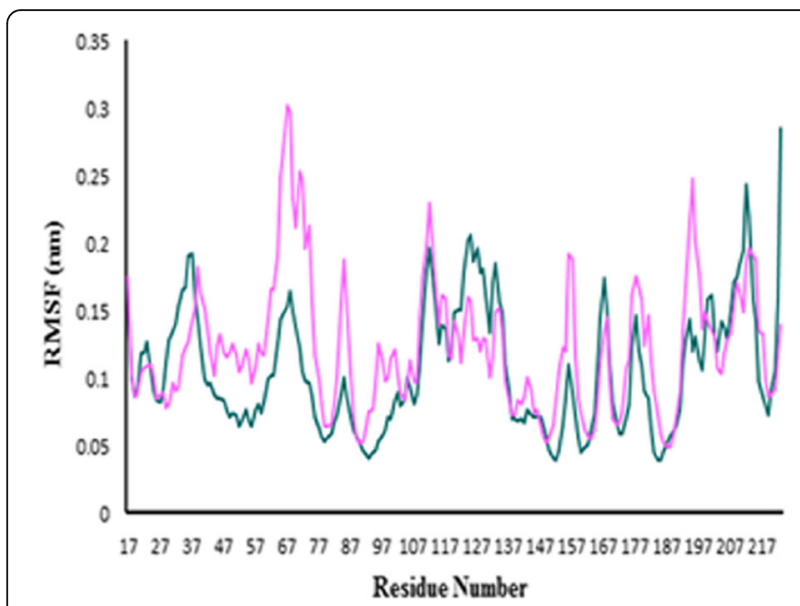

Fig. 12 The RMSF plot. Hsp90-compound 69 (violet), Hsp90-predicted ligand II (green)

toward out of pocket and was not involved in interactions between ligand and protein. Since the beginning until the half of simulation (0-25 ns), the hydrogen bond was built with crystallography water molecules in both compounds. In compound 69 , at the end of simulation (50 ns), the $\mathrm{N}$ atom of isoxazole ring and the resorcinol hydroxyl group made hydrogen bonds with Asp93 but the crystallography water molecules was not involved in interactions between ligand and protein. Adding amine group to benzothiophene moiety, conformation of predicted ligand changed and the interaction between ligand and the crystallography water molecule was seen with $1.88 \AA$ distance. According to the MD simulation analysis and also the evaluation of the interactions between compound 69 and predicted ligand II with Hsp90, adding amine group was effective in improving of binding energy of ligand and protein.

\section{Conclusion}

In current study, quantitative relationships between the molecular structure and Hsp90 inhibitory activity of 3, 4-isoxazolediamide derivative were verified by MLR and GA-PLS. In MLR, the connectivity index (X5A) has a significant effect on the inhibitory activity. This method made suitable results for the prediction set. In addition to MLR, genetic algorithm method was used which illustrated much more promising results in comparison with stepwise regression. It can be concluded from the two methods that structural features of the molecule such as size, shape, symmetry, and branching are particularly important in design of new Hsp90 inhibitors based on 3,4-isoxazolediamide scaffold. The molecular docking

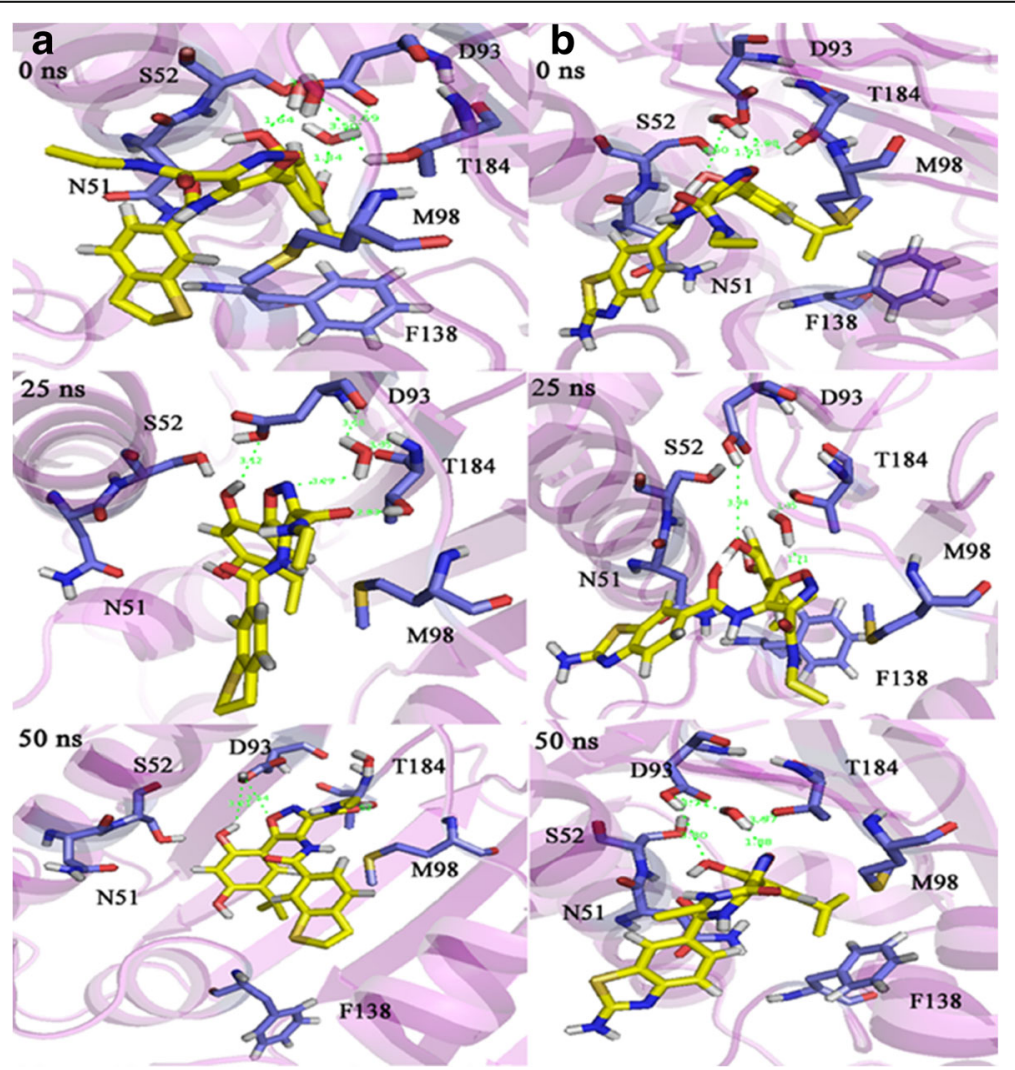

Fig. $133 \mathrm{D}$ plots of the interaction between two ligands and Hsp90 at different times during the MD simulation. Column a The interaction of compound 69 with Hsp90. Column b the interaction of the predicted ligand II with Hsp90 
simulation was also done for 25 compounds in three groups (A, B and C).

Based on QSAR models and molecular docking analysis were predicted three novel compounds. The ligand II was chosen in term of binding energy and steric orientation. Molecular dynamic simulation was done and analyses such as RMSD, RMSF and Rg, displayed that proposed ligand II, is stable in the Hsp90 active sites.

\begin{abstract}
Abbreviations
ATP: Adenosine triphosphate; CDFS: Combined data splitting-features election; GA-PLS: Genetic algorithm partial least squares; Hsp90: Heat shock protein90; MDs: Molecular dynamic simulation; MLR: Multiple linear regression; QLOoO: Square correlation coefficient for leave-one-out crossvalidation; QSAR: Quantitative structure activity relationship; $R^{2} c$ : Calibration correlation coefficient; $R_{0}^{2}$ : Prediction correlation coefficient; Rg: Gyration radius; $\mathrm{RMS}_{\mathrm{CV}}$ : Root mean square error of cross-validation; RMSF: Root mean square fluctuation; RSMD: Root-mean-square deviation; S.E: Standard error of calibration
\end{abstract}

\section{Acknowledgements}

We gratefully acknowledge the financial support from Tehran University of Medical Sciences.

\section{Funding}

Research Council of Tehran University of Medical sciences, Tehran, Iran.

\section{Availability of data and materials}

Data sharing not applicable to this article as no datasets were generated or analyzed during the current study.

\section{Authors' contributions}

MA: Participated in the design of the study, carried out the QSAR study, performed molecular docking, molecular dynamic simulation and drafted the manuscript. HAS: Participated in the design of the study drafted the manuscript and also provide financial and administrative support. MA: Was responsible for the study design and also gave final approval of the version to be published. All authors read and approved the final manuscript.

\section{Competing interests}

The authors declare that they have no competing interests.

\section{Consent for publication}

Not applicable.

Ethics approval and consent to participate

Not applicable.

\section{Publisher's Note}

Springer Nature remains neutral with regard to jurisdictional claims in published maps and institutional affiliations.

Received: 17 November 2016 Accepted: 7 June 2017

Published online: 30 June 2017

\section{References}

1. Ballante F, Caroli A, Wickersham RB III, Ragno R. Hsp90 inhibitors, part 1: definition of 3-D QSAutogrid/R models as a tool for virtual screening. J Chem Inf Model. 2014;54(3):956-69.

2. Liu J, Wang F, Ma Z, Wang X, Wang Y. Structural determination of three different series of compounds as Hsp90 inhibitors using 3D-QSAR modeling, molecular docking and molecular dynamics methods. Int J Mol Sci. 2011;12(2):946-70.

3. Verma S, Singh A, Mishra A. Dual inhibition of chaperoning process by taxifolin: molecular dynamics simulation study. J Mol Graph Model. 2012;37:27-38.

4. Simunovic M, Voth GA. Molecular and thermodynamic insights into the conformational transitions of Hsp90. Biophys J. 2012;103(2):284-92.
5. McLaughlin SH, Sobott F, Z-p Y, Zhang W, Nielsen PR, Grossmann JG, et al. The co-chaperone p23 arrests the Hsp90 ATPase cycle to trap client proteins. J Mol Biol. 2006;356(3):746-58.

6. Galam L, Hadden MK, Ma Z, Ye Q-Z, Yun B-G, Blagg BS, et al. High-throughput assay for the identification of Hsp90 inhibitors based on Hsp90-dependent refolding of firefly luciferase. Bioorg Med Chem. 2007;15(5):1939-46.

7. Jensen MR, Schoepfer J, Radimerski T, Massey A, Guy CT, Brueggen J, et al. NVP-AUY922: a small molecule HSP90 inhibitor with potent antitumor activity in preclinical breast cancer models. Breast Cancer Res. 2008;10(2):R33.

8. Baruchello R, Simoni D, Grisolia G, Barbato G, Marchetti P, Rondanin R, et al. Novel 3, 4-isoxazolediamides as potent inhibitors of chaperone heat shock protein 90. J Med Chem. 2011;54(24):8592-604.

9. Ganesh T, Min J, Thepchatri P, Du Y, Li L, Lewis I, et al. Discovery of aminoquinolines as a new class of potent inhibitors of heat shock protein 90 (Hsp90): synthesis, biology, and molecular modeling. Bioorg Med Chem. 2008;16(14):6903-10

10. O'Boyle NM, Knox AJ, Price TT, Williams DC, Zisterer DM, Lloyd DG, et al. Lead identification of $\beta$-lactam and related imine inhibitors of the molecular chaperone heat shock protein 90 . Bioorg Med Chem. 2011;19(20):6055-68.

11. Taldone T, Patel HJ, Bolaender A, Patel MR, Chiosis G. Protein chaperones: a composition of matter review (2008-2013). Expert opinion on therapeutic patents. 2014;24(5):501-18.

12. Tzanetou E, Liekens S, Kasiotis KM, Melagraki G, Afantitis A, Fokialakis N, et al. Antiproliferative novel isoxazoles: modeling, virtual screening, synthesis, and bioactivity evaluation. Eur J Med Chem. 2014;81:139-49.

13. FitzGerald GA. Anticipating change in drug development: the emerging era of translational medicine and therapeutics. Nat Rev Drug Discov. 2005;4(10):815-8.

14. Bagherzadeh K, Shirgahi Talari F, Sharifi A, Ganjali MR, Saboury AA, Amanlou M (2014) A new insight into mushroom tyrosinase inhibitors: docking, pharmacophore-based virtual screening, and molecular modeling studies. J Biomol Struct Dyn. (ahead-of-print):1-15.

15. Abbasi M, Ramezani F, Elyasi M, Sadeghi-Aliabadi H, Amanlou M. A study on quantitative structure-activity relationship and molecular docking of metalloproteinase inhibitors based on L-tyrosine scaffold. DARU Journal of Pharmaceutical Sciences. 2015;23(1):1-10.

16. Hansch C, Kurup A, Garg R, Gao H. Chem-bioinformatics and QSAR: a review of QSAR lacking positive hydrophobic terms. Chem Rev. 2001;101(3):619-72.

17. Kroemer RT. Structure-based drug design: docking and scoring. Current Protein and Peptide Science. 2007;8(4):312-28.

18. Aparoy P, Reddy KK, Reddanna P. Structure and ligand based drug design strategies in the development of novel 5-LOX inhibitors. Curr Med Chem. 2012;19(22):3763.

19. Frisch M, Trucks G, Schlegel H, Scuseria G, Robb M, Cheeseman J, et al. Gaussian 98, revision a. 7. Pittsburgh: Gaussian, Inc; 1998. p. 12.

20. Morris GM, Huey R, Lindstrom W, Sanner MF, Belew RK, Goodsell DS, et al. AutoDock4 and AutoDockTools4: automated docking with selective receptor flexibility. J Comput Chem. 2009:30(16):2785-91.

21. Bruncko M, Tahir SK, Song X, Chen J, Ding H, Huth JR, et al. N-arylbenzimidazolones as novel small molecule HSP90 inhibitors. Bioorg Med Chem Lett. 2010;20(24):7503-6.

22. Azizian H, Bahrami $H$, Pasalar $\mathrm{P}$, Amanlou M. Molecular modeling of helicobacter pylori arginase and the inhibitor coordination interactions. J Mol Graph Model. 2010;28(7):626-35.

23. Cosconati S, Forli S, Perryman AL, Harris R, Goodsell DS, Olson AJ. Virtual screening with AutoDock: theory and practice. Expert Opin Drug Discovery. 2010;5(6):597-607.

24. Morris GM, Goodsell DS, Halliday RS, Huey R, Hart WE, Belew RK, et al. Automated docking using a Lamarckian genetic algorithm and an empirical binding free energy function. J Comput Chem. 1998;19(14):1639-62.

25. Abbasi M, Sadeghi-Aliabadi H, Hassanzadeh F, Amanlou M. Prediction of dual agents as an activator of mutant p53 and inhibitor of Hsp90 by docking, molecular dynamic simulation and virtual screening. J Mol Graph Model. 2015;61:186-95

26. Abraham MJ, Murtola T, Schulz R, Páll S, Smith JC, Hess B, et al. GROMACS: high performance molecular simulations through multi-level parallelism from laptops to supercomputers. SoftwareX. 2015;1:19-25.

27. Chovancova E, Pavelka A, Benes P, Strnad O, Brezovsky J, Kozlikova B, Gora A, Sustr V, Klvana M, Medek P (2012) CAVER 3.0: a tool for the analysis of transport pathways in dynamic protein structures. 
28. Søndergaard CR, Olsson MH, Rostkowski M, Jensen JH. Improved treatment of ligands and coupling effects in empirical calculation and rationalization of p K a values. J Chem Theory Comput. 2011;7(7):2284-95.

29. Tropsha A, Gramatica P, Gombar VK. The importance of being earnest: validation is the absolute essential for successful application and interpretation of QSPR models. QSAR \& Combinatorial Science. 2003;22(1):69-77.

30. Consonni V and Todeschini R. Molecular discriptors. In: Puzyn T, Leszczynski J, Cronin MT editors. Recent advances in QSAR studies: methods and applications, vol 8. London: Springer Science \& Business Media; 2010. p.29-93

31. Fernández M, Caballero J. Modeling of activity of cyclic urea HIV-1 protease inhibitors using regularized-artificial neural networks. Bioorg Med Chem. 2006;14(1):280-94

32. Stebbins CE, Russo AA, Schneider C, Rosen N, Hartl FU, Pavletich NP. Crystal structure of an Hsp90-geldanamycin complex: targeting of a protein chaperone by an antitumor agent. Cell. 1997;89(2):239-50.

33. Prodromou C, Roe SM, O'Brien R, Ladbury JE, Piper PW, Pearl LH. Identification and structural characterization of the ATP/ADP-binding site in the Hsp90 molecular chaperone. Cell. 1997;90(1):65-75.

34. Obermann WM, Sondermann H, Russo AA, Pavletich NP, Hartl FU. In vivo function of Hsp90 is dependent on ATP binding and ATP hydrolysis. J Cell Biol. 1998;143(4):901-10.

\section{Submit your next manuscript to BioMed Central} and we will help you at every step:

- We accept pre-submission inquiries

- Our selector tool helps you to find the most relevant journal

- We provide round the clock customer support

- Convenient online submission

- Thorough peer review

- Inclusion in PubMed and all major indexing services

- Maximum visibility for your research

Submit your manuscript at www.biomedcentral.com/submit 